\title{
Reducing the Infant Mortality Rate of India to 20 by 2020: Together we can do
}

\author{
S SACHIDANANDA KAMATH \\ National President - 2015, Indian Academy of Pediatrics. \\ drsskamath@gmail.com
}

$\mathrm{O}$ ver the years, India has attained impressive achievements in child survival. A fast decline in Infant mortality rate (IMR) of country has been observed in recent past. The IMR has dropped by an average rate of $4.56 \%$ per year over last five years [1]. However, at the current pace, the country will miss the target to achieve the fourth Millennium Development Goal (MDG-4), which aims to reduce under-five mortality rate and IMR by two-thirds between 1990 and 2015. Currently, almost all countries of the South East Asia Region have lower IMR than that of India [2]. Though sixty years ago, India and China had almost the same IMR, the current IMR in China is just one-fourth of India's IMR. China has reduced its IMR by $75 \%$ as compared to that of 1990, while India could reduce it only by 53\% [2]. Within India, there exists a large variation in the current rates and percentage reduction in the IMR [1]. In India, the overall decline in child mortality was largely hindered by subdued progress in the area of neonatal deaths, especially within the first week of birth. Averting neonatal deaths is pivotal in reducing child mortality. Three major causes contribute to about 75 per cent of all deaths in the new born period: prematurity, birth asphyxia and infections [3].

Using Auto Regressive Intensive Moving Average technique, UNICEF estimated the IMR of India at 2020 as 35/1000 live births (Fig. 1) [4]. Accelerating reduction in infant mortality calls for new approaches that goes beyond disease-, program-, and sector-specific approaches. We require a comprehensive approach, including increasing the coverage of key child survival interventions. Targeted interventions focussing on poorly performing areas and increased investment in maternal and child health is needed. Strengthening of Primary health care in real sense, based on the principles of equitable distribution, inter-sectoral coordination, community participation and appropriate technology, will be the cornerstone of interventions. Commitment to improve the health and wellbeing of every infant is important, and it needs collective action.
Infant mortality is the result of a complex web of determinants at different levels. There are about 23 child survival interventions with sufficient evidence to reduce under-five mortality, as described in Lancet Child survival series II [5]. These include exclusive breast feeding, complementary feeding, safe water, Hemophilus influenzae b vaccine, zinc, vitamin A, antenatal steroids for preterm labour, newborn temperature management, tetanus toxoid, nevirapine for HIV-infected, antibiotics for premature rupture of membrane, clean delivery, measles vaccine, oral rehydration therapy, antibiotics for pneumonia, sepsis and dysentery, and newborn resuscitation. Lancet neonatal survival series has shown that scaling up of peri-conceptional folic acid supplementation to reduce the incidence of neural tube defects, calcium supplementation to reduce eclampsia, detection and treatment of asymptomatic bacteriuria, community-based pneumonia management, and extra care for low birth weight infants, including Kangaroo mother care will lead to reduction in neonatal mortality [6].

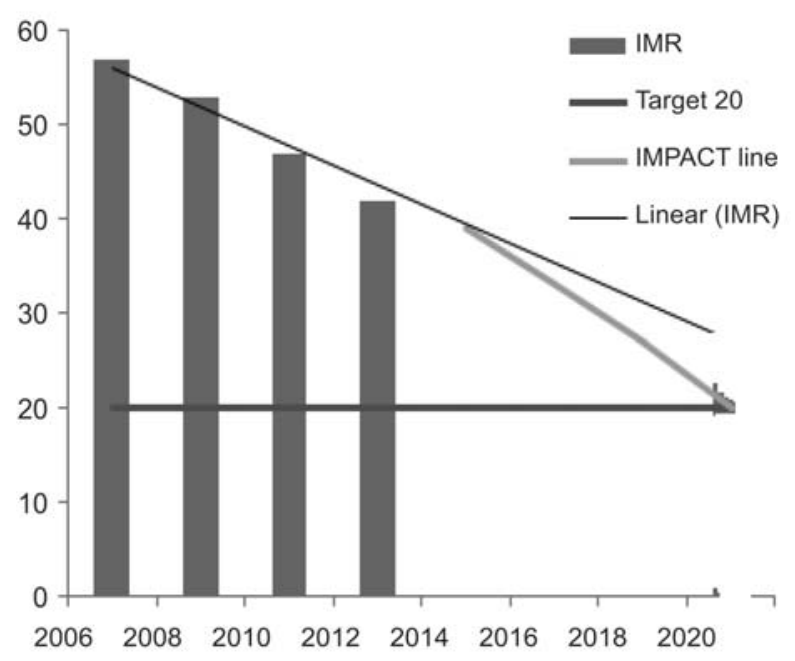

FIG. 1 Accelerating the progress of reduction in IMR of India by Mission 20/20 initiative 
Indian Academy of Pediatrics (IAP) has joined hands with Government in many initiatives, and has been involved in critical appraisal of Child health programs initiated by Central and State Governments. IAP has proposed mission 20/20 to accelerate the reduction in IMR with a target to achieve an IMR of 20 by the year 2020. By initiating Mission 20/20, the IAP has expressed its willingness to dedicate its efforts and resources to catalyze the reduction of IMR in the country. We believe that this initiative will boost the energy and enthusiasm of all stakeholders to accomplish the noble mission of attaining the target IMR of 20 by 2020 .

I know it is difficult to achieve this mission, but I am sure that it is possible. Let us join our hands for this noble mission to make sure that many more children to be born in our country celebrate their first birthday.

\section{REFERENCES}

1. Estimates of Birth Rate, Death Rate, Natural Growth Rate, Infant Mortality Rate and Total Fertility Rate by Residence, 1972-2013. SRS, Registrar General, Vol.48
No.2 September, 2013, India \& SRS-2012 (Sept., 13). Available from: http://planningcommission.nic.in/data/ datatable/1203/table_182.pdf. Accessed February 17, 2015.

2. UN Inter-agency Group for Child Mortality Estimation (UNICEF, WHO, World Bank, UN DESA Population Division). Levels and trends in child mortality. Available from: www.childmortality.org. Accessed February 13, 2015.

3. Lahariya C, Sudfeld CR, Lahariya D, Tomar SS. Causes of child deaths in India, 1985-2008: A systematic review of literature. Indian J Pediatr. 2010;77:1303-11.

4. NIMS, ICMR and UNICEF, 2012. Infant and Child Mortality in India: Levels, Trends and Determinants. New Delhi. Available from: http://www.unicef.org/india/ Report.pdf. Accessed February 17, 2015.

5. Jones G, Steketee RW, Black RE, Bhutta ZA, Morris SS; Bellagio Child Survival Study Group. How many child deaths can we prevent this year? Lancet. 2003;362:65-71.

6. Darmstadt GL, Bhutta ZA, Cousens S, Adam T, Walker N, de Bernis L; Lancet Neonatal Survival Steering Team. Evidence-based, cost-effective interventions: How many newborn babies can we save? Lancet. 2005;365:977-88.

\section{New Section in Indian Pediatrics Clinical Video of the Month}

Under this section,Indian Pediatrics will publish videos depicting an intricate technique or an interesting clinical manifestation, which are difficult to describe clearly in text or by pictures. A video file submitted for consideration for publication should be of high resolution and should be edited by the author in final publishable format. MPEG or MP4 formats are acceptable. The maximum size of file should be $20 \mathrm{MB}$. The file should not have been published elsewhere, and will be a copyright of Indian Pediatrics, if published. For this section, there should be a write-up of up to 250 words discussing the condition and its differential diagnoses. The write up should also be accompanied by a thumbnail image for publication in the print version and PDF. Submit videos as separate Supplementary files with your main manuscript. A maximum of three authors are permissible for this section. In case the video shows a patient, he/she should not be identifiable. In case the identification is unavoidable, or even otherwise, each video must be accompanied by written permission of parent/guardian, as applicable. Authors are responsible for obtaining participant consent-to-disclose forms for any videos of identifiable participants, and should edit out any names mentioned in the recording. The consent form should indicate its purpose (publication in the journal in print and online, with the understanding that it will have public access) and the signed consent of the parent/legal guardian. The copy of the consent form must be sent as supplementary file along with the write-up, and original form should be retained by the author. A sample consent form is available at our website www.indianpediatrics.net. 